\title{
Hox gene control of segment-specific bristle patterns in Drosophila
}

\author{
Marion Rozowski and Michael Akam ${ }^{1}$ \\ Laboratory for Development and Evolution, University Museum of Zoology, Department of Zoology, University \\ of Cambridge, Cambridge CB2 3EJ, UK
}

\begin{abstract}
Hox genes specify the different morphologies of segments along the anteroposterior axis of animals. How they control complex segment morphologies is not well understood. We have studied how the Hox gene Ultrabithorax $(U b x)$ controls specific differences between the bristle patterns of the second and third thoracic segments (T2 and T3) of Drosophila melanogaster. We find that $U b_{x}$ blocks the development of two particular bristles on $\mathrm{T} 3$ at different points in sensory organ development. For the apical bristle, a precursor is singled out and undergoes a first division in both the second and third legs, but in the third leg further differentiation of the second-order precursors is blocked. For the posterior sternopleural bristle, development on T3 ceases after proneural cluster initiation. Analysis of the temporal requirement for $U b x$ shows that in both cases $U b x$ function is required shortly before bristle development is blocked. We suggest that interactions between $U b_{x}$ and the bristle patterning hierarchy have evolved independently on many occasions, affecting different molecular steps. The effects of $U b x$ on bristle development are highly dependent on the context of other patterning information. Suppression of bristle development or changes in bristle morphology in response to endogenous and ectopic Ubx expression are limited to bristles at specific locations.
\end{abstract}

[Key Words: Drosophila; Hox; Ubx; sensory organs; bristle; context]

Received October 26, 2001; revised version accepted March 5, 2002.

Hox genes play a major role in generating the diversity of segment morphology along the anteroposterior axis in arthropods. Hox gene mutations can result in complete transformations of one segment into the likeness of another, affecting a multitude of characters which differ between segments. For instance, loss of Ultrabithorax $(U b x)$ function in the imaginal tissues of the fly Drosophila melanogaster causes a transformation of the third thoracic segment (T3) to resemble the second (T2): the haltere is transformed to wing, while the shape, size and bristle pattern of the T3 leg and body wall all resemble those of T2 (Lewis 1963). The complexity of this transformation requires us to explain how, in normal development, one transcription factor-the Ubx protein-can instruct all the unique characteristics of the third thoracic segment, affecting many distinct developmental processes.

In the insect thorax and abdomen, the developmental instructions for establishing segments are initially independent of the instructions that specify the differences between segments (Akam 1987). The expression of segment polarity and dorsoventral patterning genes in Drosophila does not require Hox gene function, and is similar in each trunk segment (Chasan and Anderson 1993;

${ }^{1}$ Corresponding author.

E-MAIL akam@mole.bio.cam.ac.uk; FAX 44-1223-336679.

Article and publication are at http://www.genesdev.org/cgi/doi/10.1101/ gad.219302.
Martinez Arias 1993). It constitutes a common segmental ground plan that, in the absence of all Hox gene function, generates a default arthropod segment, with cuticular plates, jointed appendages, etc. (Lewis 1978; Stuart et al. 1991).

In only a few cases do we know how the Hox genes modify this default developmental program. One such case is the control of ventral appendage development in the abdomen. In this case, early expression of either the $U b x$ or the $a b d-A$ Hox gene in cells of the presumptive appendage primordium represses distalless expression, and so blocks formation of the appendage which is a part of the default program (Vachon et al. 1992). The modification of appendage development under homeotic gene control has also been studied in some detail. Hox genes act at multiple points in the genetic network that controls the differential developmental trajectories that result in leg versus antennal development (Wagner-Bernholz et al. 1991; Casares and Mann 1998), and haltere versus wing development (Weatherbee et al. 1998; Roch and Akam 2000). They collaborate with genes that function in all appendages to instruct appendage-specific development (Gorfinkiel et al. 1997).

In the present study we examined how the Hox gene $U b x$ modulates the bristle pattern in the legs and lateral body wall of $D$. melanogaster. Bristles are chemosensory and mechanosensory organs of the peripheral nervous system. They are abundant on all fly segments but dif- 
ferentially distributed between segments. Among the mechanosensory bristles there is a clear morphological distinction between large bristles (macrochaetes) and small bristles (microchaetes). Ubx is expressed in both the second and third leg imaginal discs. In both discs, expression levels are modulated throughout development but levels are consistently much higher in the third leg disc than in the second (Brower 1987).

The legs retain the same basic structure in each thoracic segment, with an identical number of leg segments and joints. This allows precisely corresponding parts of different legs to be identified without difficulty. Many characteristics of the bristle pattern are also directly comparable between the legs-notably the morphologically distinct macrochaetes that occur at specific positions with respect to these other landmarks. Thus they are assumed to be homologous elements of the pattern on different legs, and are given generic names ("tibial apical bristle" etc.). Individual macrochaetes may be present on all legs in one species, but only on one or two leg pairs in another species (Wheeler 1981).

The three leg discs develop in parallel as imaginal discs within the body of the larva. These show coordinate changes in morphology and gene expression patterns (Auerbach 1936; Cohen 1993; Goto and Hayashi 1997). Patterning of the imaginal discs ultimately provides instructions for the initiation of bristle development through the formation of proneural clustersgroups of cells characterized by the expression of two genes of the achaete-scute complex (AS-C): achaete (ac) and scute $(s c)$. The patterning information that defines the position of proneural clusters comprises a diverse array of positive and negative regulators which act through site-specific enhancer elements distributed along the AS-C (Gomez-Skarmeta et al. 1995). All the cells in a proneural cluster are competent to give rise to sensory organs (Heitzler and Simpson 1991). Lateral inhibition among these cells prevents most cells from acquiring a definitive sensory organ fate. The singling out of an individual precursor from the proneural cluster is gated by a general enhancer within the AS-C complex which is distinct from the specific enhancers that promote proneural cluster formation (Culi and Modolell 1998). Once singled out, the sensory organ precursors undergo a series of stereotyped divisions. In the case of mechanosensory organs, the first division generates two second-order precursors, one of which will give rise to the external cells of the bristle, the shaft, and the socket, whereas the other will give rise to a neuron, a glia cell, and a neuron sheath cell (Gho et al. 1999).

The parallel development of the three pairs of legs allows precise definition of the points at which $U b x$ controls the development of leg bristle patterns. As steps of sensory organ development are discrete and stereotyped we can ask, for each bristle affected, where in the program $U b x$ modifies the default pathway. In this way we can assess whether there are general rules for how $U b x$ interacts with bristle development. Knowledge of the mechanisms underlying such interaction will allow us to envisage how morphology may evolve between seg- ments of a species-in the case of this study for example how bristle patterns may diversify between segments.

We have concentrated on three large mechanosensory bristles that differ between the second and third thoracic segment-the posterior macrochaete on the sternopleurum, and the apical and preapical bristles on the tibia. In D. melanogaster, the sternopleural bristles and the apical bristle on the tibia are found only on T2. The preapical bristle on the tibia is found on both second and third legs, but it has a different morphology on these two legs. In flies mutant for adult function of $U b x$ (e.g., $b x 3 /$ Ubx1), both second and third thoracic segments display the wild-type pattern of the T2 segment for these bristle traits. For each of these bristles, we examined when the differences between the T2 and T3 segments are laid down, and when Ubx functions in relation to the program of sensory organ development.

\section{Results}

\section{The timing of leg bristle development}

In wild-type flies, apical and sternopleural bristles appear only on the second thoracic segment, but in $U b x$ mutant flies, they also develop on the third thoracic segment. Thus, directly or indirectly, Ubx normally blocks the development of these bristles on the third leg. To determine when the block of development occurs for the apical and the posterior sternopleural macrochaete, we monitored early stages of sensory organ development. We started by looking for segregated sensory organ precursors.

The precursors for different types of sensory organs can be distinguished by the combination of markers they express. A reporter construct in the neuralized gene, $n e u-l a c Z$, is expressed in all sensory organ precursors. The homeodomain protein Cut is expressed only in the precursors for external sensory organs, and thus allows us to distinguish between external and internal sensory organs (e.g., the chordotonal organs). Among the external sensory organs, chemosensory bristle precursors can be distinguished from mechanosensory precursors by their expression of the paired box protein Pox-neuro. In the folded disc epithelium, the individual mechanosensory precursors can be identified by their location in relation to markers of joint territory and other landmarks in the discs. When the legs elongate, the identity of the sensory organ precursors can be assessed by comparing the position of labeled cells with that of sensory organs in the adult leg segments. In the leg disc, the first bristle precursors develop during the third larval instar. These early segregating precursors include precursors for the tarsal chemosensory bristles, and for a few of the largest mechanosensory bristles in the proximal leg, including the precursor for the posterior sternopleural macrochaete. Precursors for the apical and preapical bristles appear at about the time of puparium formation, and can be detected reliably in the white prepupa (Nottebohm et al. 1994). At this time chemosensory precursors also appear in the tibia. Precursors for the smaller mechanosen- 
sory bristles are not formed until 8-12 h after puparium formation (Nottebohm et al. 1994).

Using sensory organ markers, we found that sensory organ development is blocked at different points for the apical and for the posterior sternopleural bristles. In white prepupae, no precursor cell appears in the third leg at the position corresponding to that of the sternopleural precursor in the second leg (Fig. 1F,G). However, apical bristle precursors are present on both the second and third legs (not shown, see below). We conclude that $U b x$ blocks some event leading to the specification of the posterior sternopleural bristle precursor, but that $U b x$ does not inhibit formation of the apical bristle precursor on T3.

\section{Sternopleural bristle development on T3 is blocked} during proneural cluster maturation

No segregated precursor appears for the sternopleural bristle on T3. To find out whether any earlier stage of sensory organ development is reached, we observed the course of proneural cluster development during the third larval instar. We found that a sternopleural proneural cluster forms transiently in the third leg disc, but then regresses (Fig. 1A-E). We have used a scabrous-Gal4 line driving GFP expression to observe the formation of this cluster. scabrous (sca) is a downstream target of achaete and scute (Singson et al. 1994). We recorded sternopleural proneural cluster development in three different time intervals (Fig. 1A). On the second leg, this proneural cluster first emerges between 25 and $16 \mathrm{~h}$ before puparium formation (BPF), probably around $20 \mathrm{~h}$ BPF. On the third leg, the cluster appears in the same time window as on the second leg (Fig. 1B-E). However, the percentage of clusters observed on the third leg is lower than on the second leg (31\% vs. $75 \%)$, probably because the cluster exists for only a short time. Indeed, in the time interval from $11-0 \mathrm{~h} \mathrm{BPF}$, it is no longer found on the third leg.
Sternopleural proneural clusters found in leg imaginal discs

\begin{tabular}{lcccc}
\cline { 2 - 5 } Larval age & \multicolumn{2}{c}{$\mathrm{T} 2$} & \multicolumn{2}{c}{$\mathrm{T} 3$} \\
\cline { 2 - 5 } distribution & $\%$ of & $(\mathrm{N}$ in & $\%$ of & $(\mathrm{N}$ in \\
in hrs BPF & clusters & sample) & clusters & sample) \\
\hline $31-22$ & 0 & $(10)$ & 0 & $(10)$ \\
\hline $25-16$ & 75 & $(16)$ & 31 & $(13)$ \\
\hline $11-0$ & 100 & $(12)$ & 0 & $(10)$
\end{tabular}

Figure 1. Development of the posterior sternopleural bristle in the third leg ceases after proneural cluster initiation-no precursor segregation takes place. (A) Summary table. Sternopleural proneural clusters were identified as cells staining for GFP expressed with the sca-Gal4 line. (B$E)$ Leg imaginal discs of two individuals from the time interval 25-16 h BPF during which the cluster (triangle) emerges in T2 and T3 and also disappears in T3. One individual shows a few GFP positive cells in the dorsal outer ring in the second $(B)$ and the third leg $(C)$. The other individual shows several GFP positive cells in the dorsal outer ring only in the second leg $(D)$, not in the third leg $(E)$. $(F, G)$ Sensory organ precursors at the white prepupa stage. A sternopleural bristle precursor is found in the second leg (triangle) but not the third leg. Discs of the neuralized-lacZ line were stained with anti- $\beta$-galactosidase (green) and with anti-Pox-neuro (red). In the second leg disc $(F)$, the sternopleural bristle precursor (triangle) is located in the outer ring of the disc dorsal to the large femoral chordotonal organ (asterisk).
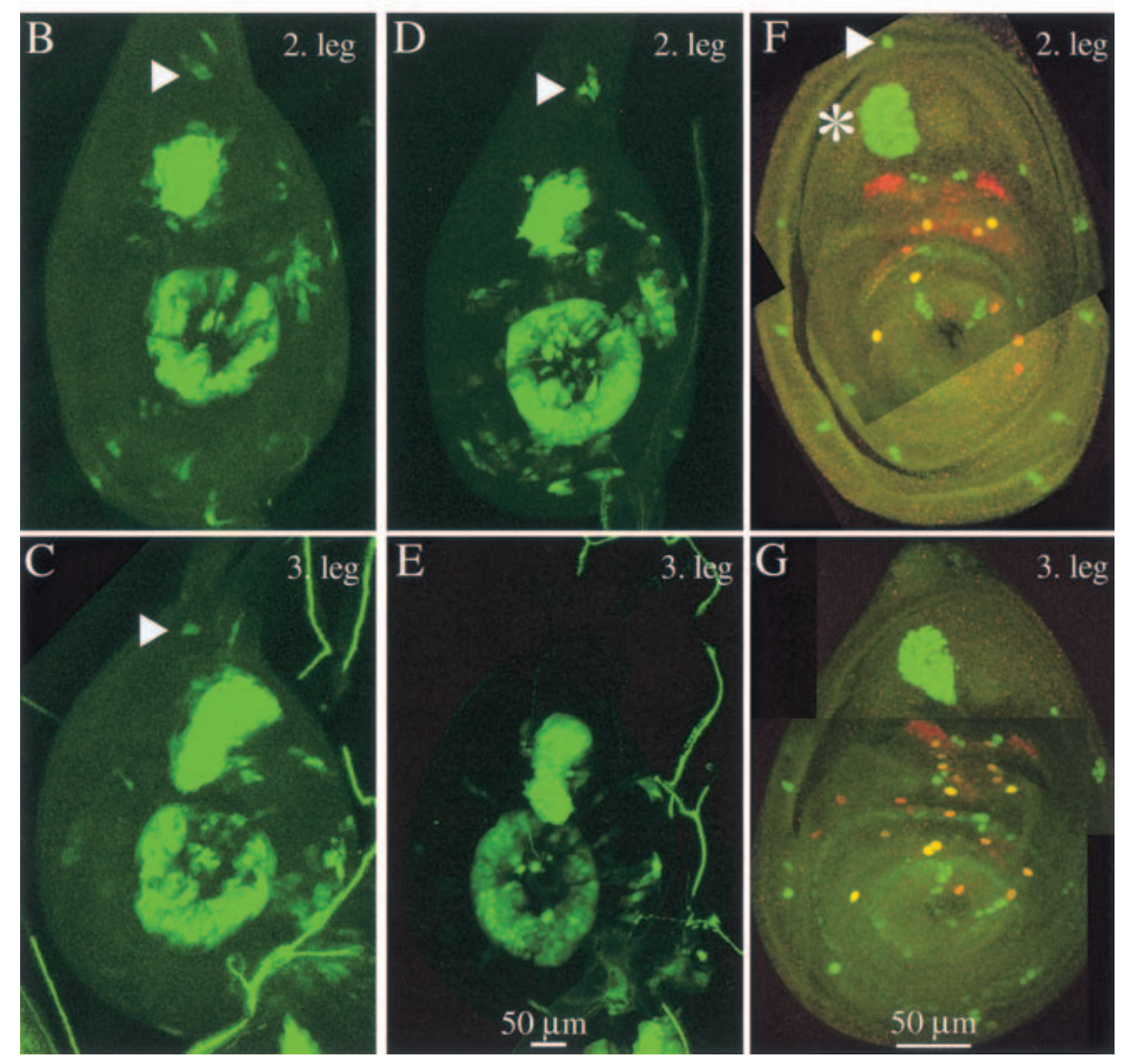
In conclusion, sensory organ development for the sternopleural bristle is initiated on T3 but halted at the stage of proneural cluster development, between 25 and $16 \mathrm{~h}$ BPF.

Ubx is required at the time of proneural cluster initiation to block development of sternopleural macrochaetes on T3

To determine when the $U b x$ gene is required to suppress development of the sternopleural bristles in the third leg, we induced $U b x$ null clones $\left(U b x^{1}\right)$ at different times during development. In a first series of experiments, we heatshocked larvae to induce expression of FLP recombinase, thereby controlling the timing of clone induction. These animals were collected as newly formed pupae, and scored for sternopleural bristle clones (marked by bristle morphology) in the adult (Fig. 2). On T2 formation of the sternopleural bristle is not affected by the presence of the $U b x$ gene, which is expressed only at low levels. Thus, scoring bristle clones on $\mathrm{T} 2$ provides a control for the success of clone induction over the entire time course. We find that $U b x$ null clones induced by heatshock up to $22-16 \mathrm{~h}$ BPF can give rise to sternopleural macrochaetes on $\mathrm{T} 3$.

The latest time when the generation of $U b x$ null clones results in the development of sternopleural macrochaetes on $\mathrm{T} 3$ coincides with the time when we see transient formation of a proneural cluster on T3. To test whether the cells of this cluster can in fact give rise to bristles, we induced $U b x$ null clones by using the scaGal4 driver to activate recombinase. Such clones should only be generated after the first division of a cell within the sternopleural proneural cluster. Sternopleural macrochaetes develop from these clones on T3 (Fig. 2E). Therefore, the neural potential of the proneural cluster cells on T3 is intact, despite expressing $U b x$ up to the point of clone induction. This shows that $U b x$ function
A

\begin{tabular}{ccccc} 
& \multicolumn{2}{c}{ \% Ubx null SP1 and SP3 bristles/ hemisegment (N) } \\
\cline { 2 - 5 } Time interval & \multicolumn{3}{c}{ T2 } & \multicolumn{2}{c}{ T3 } \\
\cline { 2 - 5 } in hrs BPF & SP1 & SP3 & SP1 & SP3 \\
\cline { 2 - 5 } & $25(40)$ & $25(40)$ & $50(40)$ & $70(40)$ \\
\hline $48-43$ & $9(23)$ & $25(24)$ & $13(24)$ & $33(24)$ \\
\hline $34-29$ & $22(23)$ & $21(24)$ & $0(24)$ & $17(24)$ \\
\hline $29-25$ & $22(41)$ & $16(38)$ & $8(38)$ & $8(38)$ \\
\hline $27-21$ & $24(42)$ & $7(42)$ & $2(42)$ \\
\hline $25-19$ & $24(38)$ & $18(38)$ & $3(38)$ & $0(38)$ \\
\hline $22-16$ & $21(14)$ & $21(14)$ & $0(14)$ & $0(14)$ \\
\hline $14-17$ & $6(51)$ & $13(53)$ & $0(54)$ & $0(54)$
\end{tabular}

B

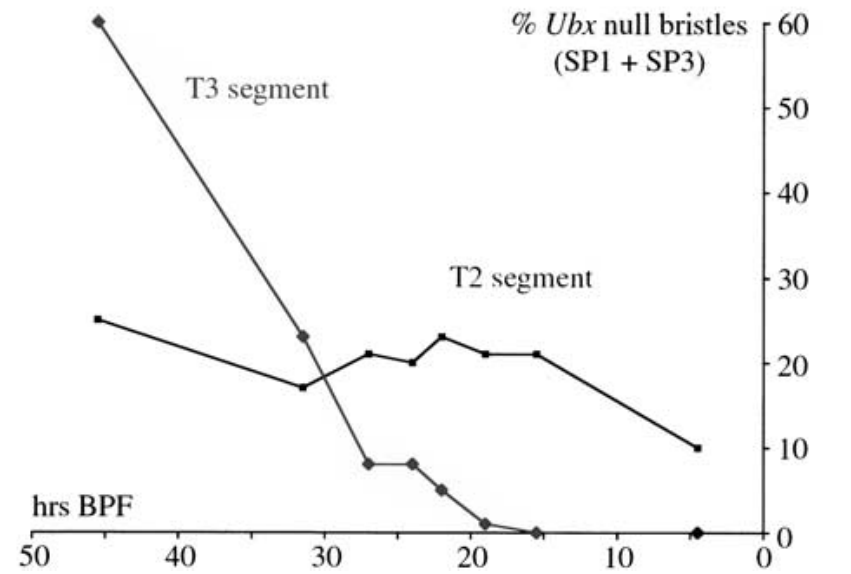

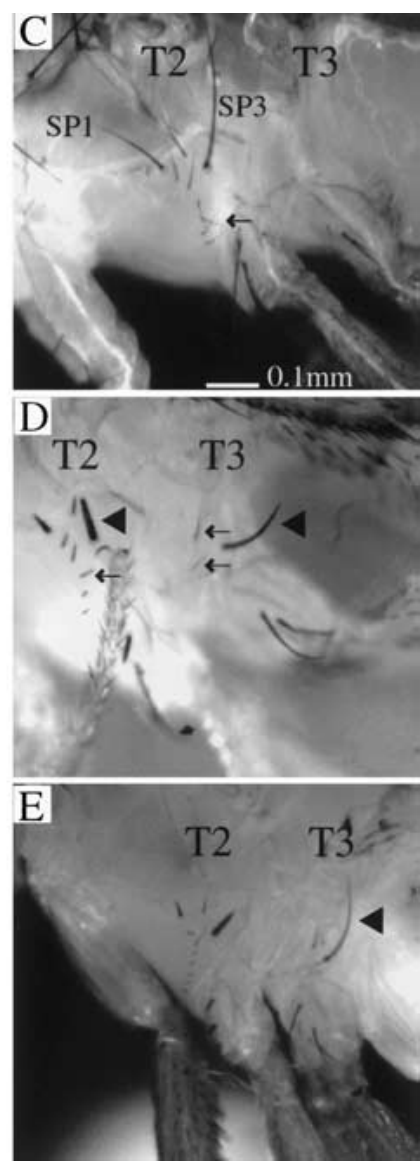

Figure 2. Formation of anterior and posterior sternopleural macrochaetes (SP1 and SP3) in T3 following timed induction of $U b x$ null clones and $U b x$ null clone induction targeted to the sternopleural proneural cluster. $(A)$ Summary table. $(B)$ Graph showing the frequency of T2 and T3 anterior and posterior sternopleural bristles as a function of the time of $U b x$ null clone induction. (C) Lateral thorax of a wild-type fly. Sternopleural bristles are found exclusively on T2 (SP1 anterior and SP3 posterior sternopleural macrochaete; the arrow points to the row of microchaetes). (D) Fly with $S b^{+}$-marked $U b x$ null clones induced with a heatshock $28 \mathrm{~h} \mathrm{BPF}$. $U b x$ null clones induced at this time give rise to sternopleural macrochaetes (triangle) and microchaetes (arrows) on T3; corresponding bristles on T2 are marked in the same way. (E) Fly with $S b^{+}$-marked $U b x$ null clones induced with the scabrous-Gal4 line. sca-Gal4 is transiently expressed in the T3 sternopleural proneural cluster when the cluster is first formed on T2 and T3. Ubx null clones generated at this time give rise to sternopleural macrochaetes on T3 (triangle in E). 
is required after formation of the sternopleural proneural cluster to block macrochaete development on T3.

These results suggested that the formation of precursors for sternopleural macrochaetes on $\mathrm{T} 2$ would be blocked by ectopic expression of Ubx protein during formation of the proneural cluster. To test this, we expressed Ubx protein under the control of a heatshock promoter (Fig. 3). We found that sternopleural precursor development on the T2 leg can be suppressed when Ubx is induced in developing second leg discs by heatshocks administered from $23 \pm 1 \mathrm{~h} \mathrm{BPF}$, and also from $21 \pm 1 \mathrm{~h} \mathrm{BPF}$ but at lower efficiency. Heatshocks from $6 \pm 1 \mathrm{~h}$ BPF do not inhibit sternopleural precursor development on $\mathrm{T} 2$. Thus, Ubx can only suppress sternopleural macrochaete

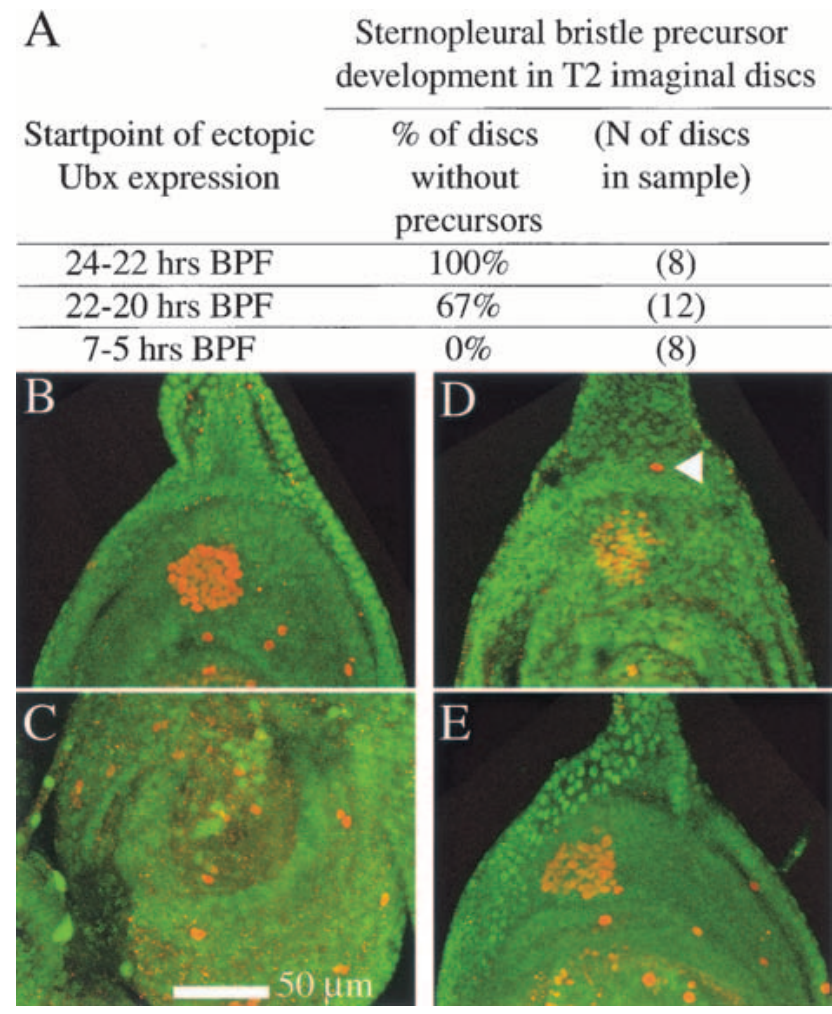

Figure 3. Ectopic Ubx expression from $24-22$ h BPF can suppress sternopleural bristle precursor development on T2, but ectopic expression from shortly before puparium formation cannot. Larvae were subjected to heatshock regimes covering different spans of third larval instar development. Larvae were examined for sensory organ precursors at a stage corresponding to the white prepupa. Precursors were visualized by staining with anti- $\beta$-galactosidase in the neuralized-lac $Z$ background (red). Ubx levels were assayed by costaining for Ubx protein (green). (A) Summary table. $(B-C)$ Individual for which the heatshock-Ubx regime started between 24 and $22 \mathrm{~h}$ BPF. (B) Second leg disc of this individual. No sternopleural bristle precursor is found in the dorsal leg periphery. $(C)$ Third leg disc of this individual. $(D-E)$ Individual for which the hs-Ubx regime started $7 \mathrm{~h} \mathrm{BPF}$. (D) Second leg discs of this animal. The sternopleural bristle precursor is present in the dorsal leg periphery (arrowhead). (E) Third leg of this animal. $(C, E)$ In both treatments, ectopic Ubx levels at the time of collection have not sunk below endogenous third leg levels. development until shortly after proneural cluster formation.

\section{Apical bristle development on T3 is blocked after the first division of the bristle mother cell}

We have seen above that sternopleural macrochaete development on T3 is blocked during proneural cluster development. In contrast, a precursor for the apical bristle is formed on the third leg, while the wild-type condition for this leg is absence of an apical bristle. We monitored the further development of this precursor by analyzing the next stages in bristle development. By $4 \mathrm{~h}$ after puparium formation $(\mathrm{APF})$, the precursors for the apical bristle have undergone a first division, giving rise to second-order precursors in all three legs (Fig. 4A-E). On the third leg, the further development of these second-order precursors is then disrupted. Sometimes a three-cell cluster can be detected, but by $5.5 \mathrm{~h} \mathrm{APF}$, expression of neural markers is fading (Fig. 4F-I). Staining with antiCut antibody is lost first, while detectable neuralized (neu)-lacZ expression persists. To assess whether the cells survive the loss of neural markers, we drove GFP expression in the precursors, using a Gal4 line inserted in the scabrous locus, 109-68 Gal4. This line drives expression in the sensory organ lineage. GFP-expressing cells can be observed for a period of time after they lose neu-lacZ expression (data not shown). We conclude that the loss of neural markers is not accomplished by cell death.

Ubx is required at several stages, prior to and in the sensory organ lineage, to suppress apical bristle development on T3

Apical bristle development is disrupted at the secondorder precursor stage. Is it also at this stage that $U b x$ effects the suppression of further bristle development? To address this question, we generated $U b x$ null secondorder precursors. We targeted the induction of $U b x$ null clones specifically to the sensory organ lineage, by using the 109-68 Gal4 line. In the development of most sensory organs, activity of the 109-68 Gal4 line is detectable in the first-order precursors but not earlier. We have confirmed this for the apical bristle (see Materials and Methods). Therefore, when this line is used to generate recombination, mitotic clones should first be produced at the division of first-order precursors. We found that apical bristle precursors which are deficient for $U b x$ from the second-order precursor stage give rise to bristle shaft and socket on the third leg (Fig. 5). We confirmed this late requirement for $U b x$ by using a timed heatshock to provide Flipase for mitotic recombination. We find that Flipase expression 0-6 h BPF can lead to the development of apical bristles on T3 (T3, 10\% presence of apical bristles, $n=29 ; \mathrm{T} 2,17 \% S b^{+}$bristles, $n=30$ ). Sensory mother cells are selected from mitotically quiescent clusters of cells arrested in G2 (Usui and Kimura 1992). As the firstorder precursor of the apical bristle is generated around 

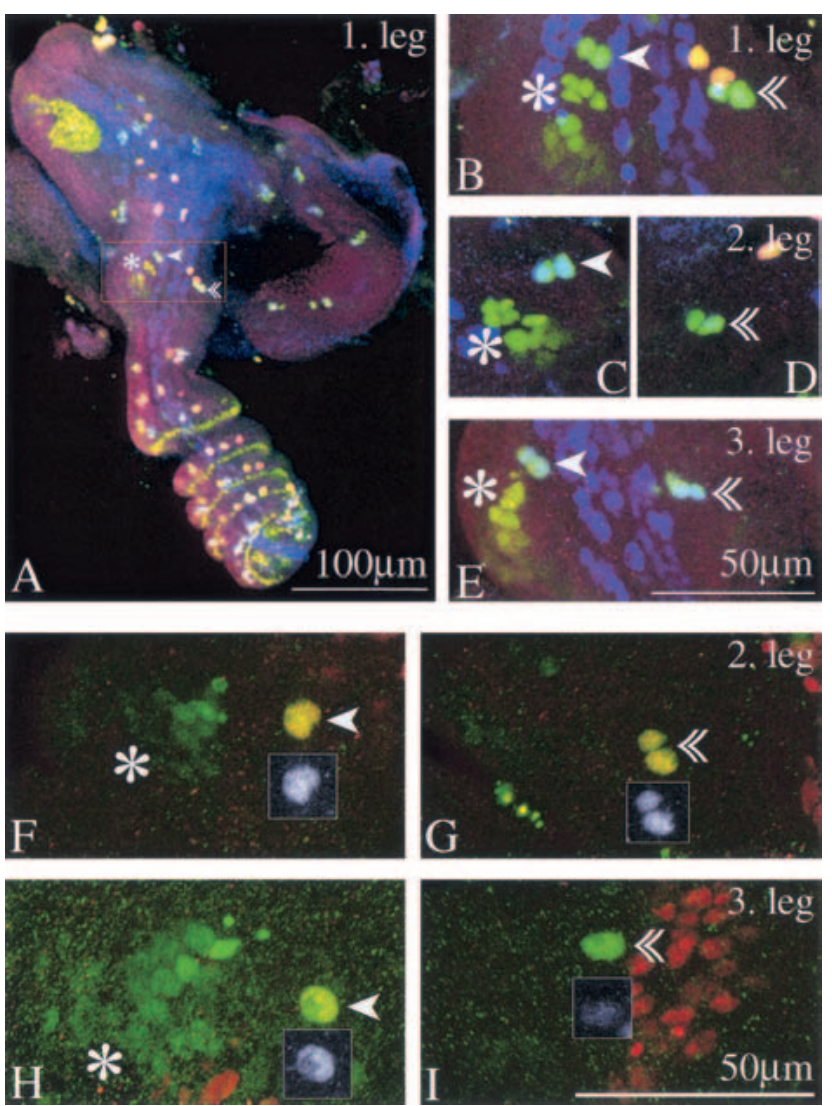

Figure 4. Second-order precursors for both the apical and the preapical bristle form on all three legs. The apical bristle precursors on T3 lose their neural markers but survive. $(A-E)$ Leg imaginal discs of the neu-lacZ line 4-4.5 h APF stained with anti- $\beta$-galactosidase (green), with anti-Pox-neuro (red) and with anti-Cut (blue). Mechanosensory bristles appear blue-green. $(A)$ First leg. The inset frames the distal tibia and is magnified in $B$. $(B-E)$ Close-up of the distal tibia in the three legs. Second-order precursors for the preapical (arrowhead) and the apical bristle (double arrowhead) are found in all three legs. Preapical bristle precursors are in close proximity to the tibial chordotonal organ precursors (asterisk). ( $F-I)$ Leg discs from a white prepupa of the neu-lacZ line, $4.5 \mathrm{~h}$ APF stained with anti- $\beta$-galactosidase (green) and anti-Cut (red). Sensory organs are marked as above. Insets show Cut expression of the precursors. $(F)$ Preapical and $(G)$ apical bristle precursors of the second leg; $(H)$ preapical and (I) apical bristle precursors of the third leg. Cut expression has faded from the apical bristle precursors in the third leg, while anti- $\beta$-galactosidase expression still marks the cells $(I)$.

the time of puparium formation, a heatshock shortly before puparium formation will provide recombinase in the quiescent proneural cluster cells from which the precursor is selected so that a $U b x$ null clone will be generated in the second-order precursors. These results show that $U b x$ is required in the second-order precursors to stop further neural development.

However, Ubx expression in the precursor lineage alone is not sufficient to instruct loss of neural identity. We used the 109-68 Gal4 line to induce ectopic expression of Ubx (protein isoform Ubx Ia) from the time of formation of the first-order precursor onwards. In this ectopic expression regime, no loss of the apical bristle on T2 occurred, despite levels of Ubx protein in the apical bristle precursors comparable with those seen in T3 (data not shown). Even much higher levels of Ubx expression (from a line expressing isoform IVa) do not block apical bristle development at the normal time (data not shown).

Yet, prolonged expression of Ubx in T2 can suppress the development of the apical bristle in a manner that mimics normal development on T3. We used a decapentaplegic (dpp)-Gal4 line to drive ectopic Ubx expression with the same UAS-Ubx line expressing isoform Ia. This dpp-Gal4 line drives Ubx expression in the domain which will give rise to the apical bristle precursor during much of imaginal disc development. In this experiment, the apical bristle is lost from T2 (45 times in 50 cases). In comparison, the preapical bristle is rarely suppressed (10 times in 50 cases) (Fig. 6E-H). Examination of second leg imaginal discs from these flies shows that in the majority of cases, precursors for the apical bristle are found initially within the Ubx-expressing domain (Fig. 6A). At the time when apical bristle precursors normally cease to express neural markers in the third leg, 5-6 h APF, the second leg precursors also show reduced levels of neural markers (anti- $\beta$-galactosidase staining in the neu-lac $Z$ line) (Fig. 6B,C). Thus, this ectopic expression regime recreates in $\mathrm{T} 2$ the course of apical bristle development normally seen in $\mathrm{T} 3$.

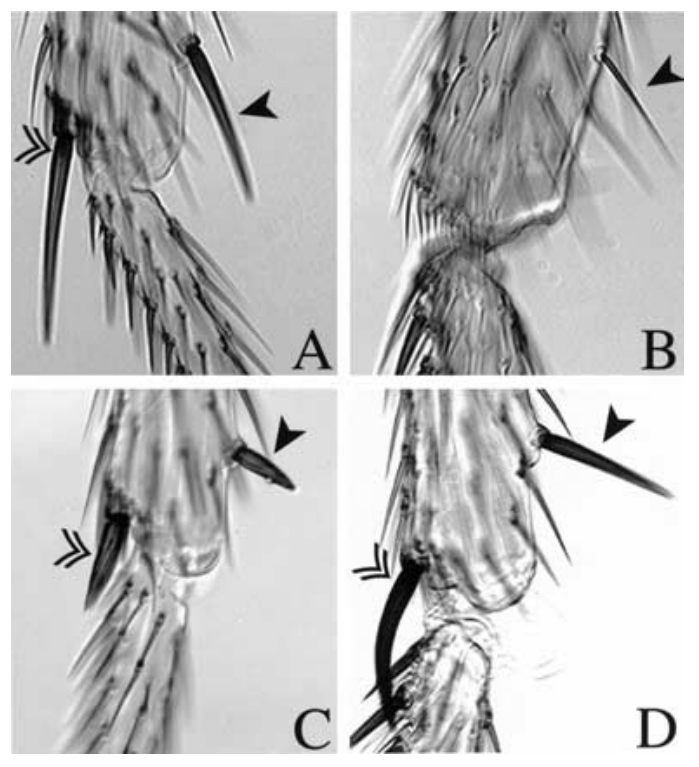

Figure 5. Removal of $U b x$ from the second-order precursors results in shaft and socket development of the apical bristle on T3 and converts preapical bristle morphology on T3 towards T2. $(A-D)$ Double arrowhead marks the apical bristle, arrowhead marks the preapical bristle. $(A)$ Wild-type second leg and $(B)$ wild-type third leg. $(C)$ Second leg of experimental animal expressing the $S b$ mutation in apical and preapical bristle. $(D)$ Third leg in which mitotic recombination driven in the sensory organ lineage resulted in $\mathrm{Sb}^{+}$macrochaetes. 

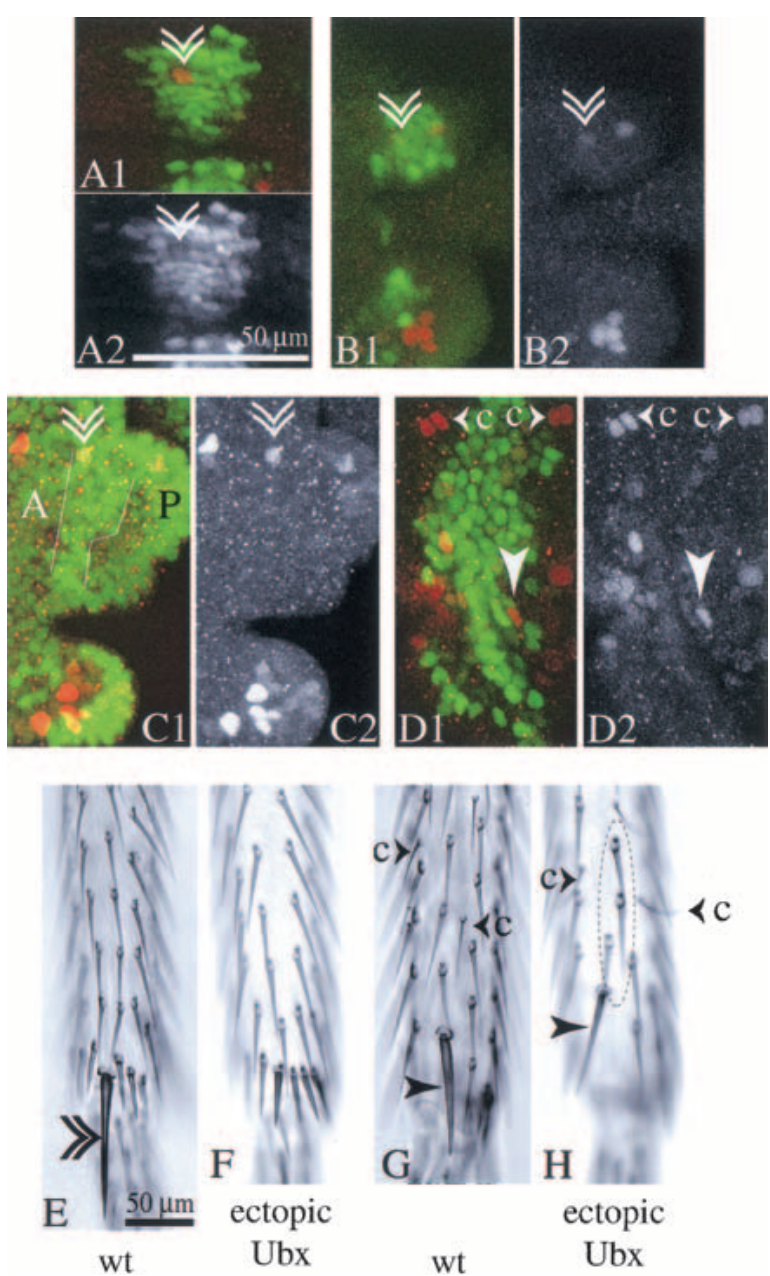

Figure 6. In a regime of prolonged ectopic Ubx expression, neural markers disappear from the apical bristle precursors on $\mathrm{T} 2$. The adult flies show selective loss of the apical bristle. $(A-D)$ Confocal images of the apical bristle precursors in prepupal legs with ectopic Ubx expression (Ubx isoform Ia) driven by $d p p$ Gal4 in the neu-lacZ background. Precursors are marked by anti- $\beta$-galactosidase staining (red), and Ubx expression is shown (green). Double arrowhead marks the apical bristle precursors, arrowhead marks the preapical bristle precursors. $(A)$ Second leg about $3 \mathrm{~h}$ APF. Second-order precursors for the apical bristle are present within the domain of ectopic Ubx expression. (A2) shows the Ubx channel. (B) Second leg 5-6 h APF. Very low levels of anti- $\beta$-galactosidase staining remain in the apical bristle precursors (see red channel in B2). Anti- $\beta$-galactosidase staining is also reduced in the apical bristle precursors of the third leg of this individual $(C)$. The stripe of ectopic Ubx expression in the third leg (white outlines in C1) compares to Ubx levels in the posterior third leg (marked P), exceeding levels in the anterior third leg (marked A). (D) In the dorsal second leg, the stripe of ectopic Ubx expression occupies most of the width between the chemosensory precursors (small arrowheads accompanied by the letter c). (E) Ventral aspect of the distal tibia of an adult wild-type fly and $(F)$ of a fly from the above regime of ectopic Ubx expression-the apical bristle is missing from the ventral side of the tibia. From the dorsal domain of ectopic Ubx expression $(D)$ the preapical bristle (arrowhead in $H$ ) and mechanosensory microchaetes on the dorsal leg (circle in $H$ ) arise normally. $(G)$ Dorsal aspect of the distal tibia of a wild-type fly.
Differences in Ubx levels are not the basis for the differential response of apical and preapical bristle precursors

The experiments above show that a precursor cell for the apical bristle is specified in the developing third leg, but the daughters of this cell lose neural markers at about 5.5 $h$ APF. The precursors for another mechanosensory bristle, the preapical bristle, develop in the same compartment of the same leg segment at a similar time, but do not cease expressing neural markers in response to Ubx: A preapical bristle appears on all three legs of the adult. How does Ubx repress the development of the apical bristle, but not the preapical bristle?

$U b x$ is widely expressed in the third leg, but it is not expressed at the same level in all cells. Thus one possible reason for the differential development of the apical and preapical bristle precursors is that they are exposed to different levels of Ubx protein, at the time when bristle development is blocked. The need for high levels of Ubx to block apical bristle development is supported by the observation that this function is partially haploinsufficient; flies heterozygous for a $U b x$ null mutation occasionally develop an apical bristle on T3 $(1.4 \%, n=138$ of T3 legs with apical bristle for $\left.U b x^{1}\right)$.

To test whether the different developmental course of the apical and preapical bristles can be explained by differences in Ubx expression, we examined Ubx levels through antibody staining. We have shown above that $U b x$ function is required in the precursors to suppress apical bristle development. Therefore we examined Ubx expression in the first- and second-order precursors of the apical and preapical bristles $2.5 \mathrm{~h} \mathrm{APF} \mathrm{(Fig.} \mathrm{7A,B)} \mathrm{and}$ $4.5 \mathrm{~h}$ APF (Fig. 7C-F). At both stages, Ubx levels are modulated in different regions of the disc. It is particularly noteworthy that sensory organ precursors can show levels of Ubx protein very different from those of the surrounding disc epithelium (see the precursors of the tibial chordotonal organ in Fig. 7B,D). However, at both time points, levels of Ubx protein in the apical bristle precursors are similar to those in the preapical bristle precursors and in the surrounding disc epithelium. Therefore, their differential developmental response cannot be attributed to differences in the levels of Ubx protein at these stages.

It remains possible that earlier differences in levels of Ubx expression contribute to the different response of these cells. However, the result of ectopically expressing Ubx in the second leg throughout much of disc development argues against this possibility. When Ubx is ectopically expressed using the $d p p$-Gal4 driver, development of the apical bristle is efficiently suppressed, but development of the preapical bristle is rarely blocked (see above). Very high levels of Ubx protein do seem to suppress the expression of neural markers to some extent in both the apical and preapical bristle precursors, but this does not lead to complete dedifferentiation in the case of the preapical bristle precursors. Thus, the response of the apical and preapical precursors to $U b x$ appears to be intrinsically different. 

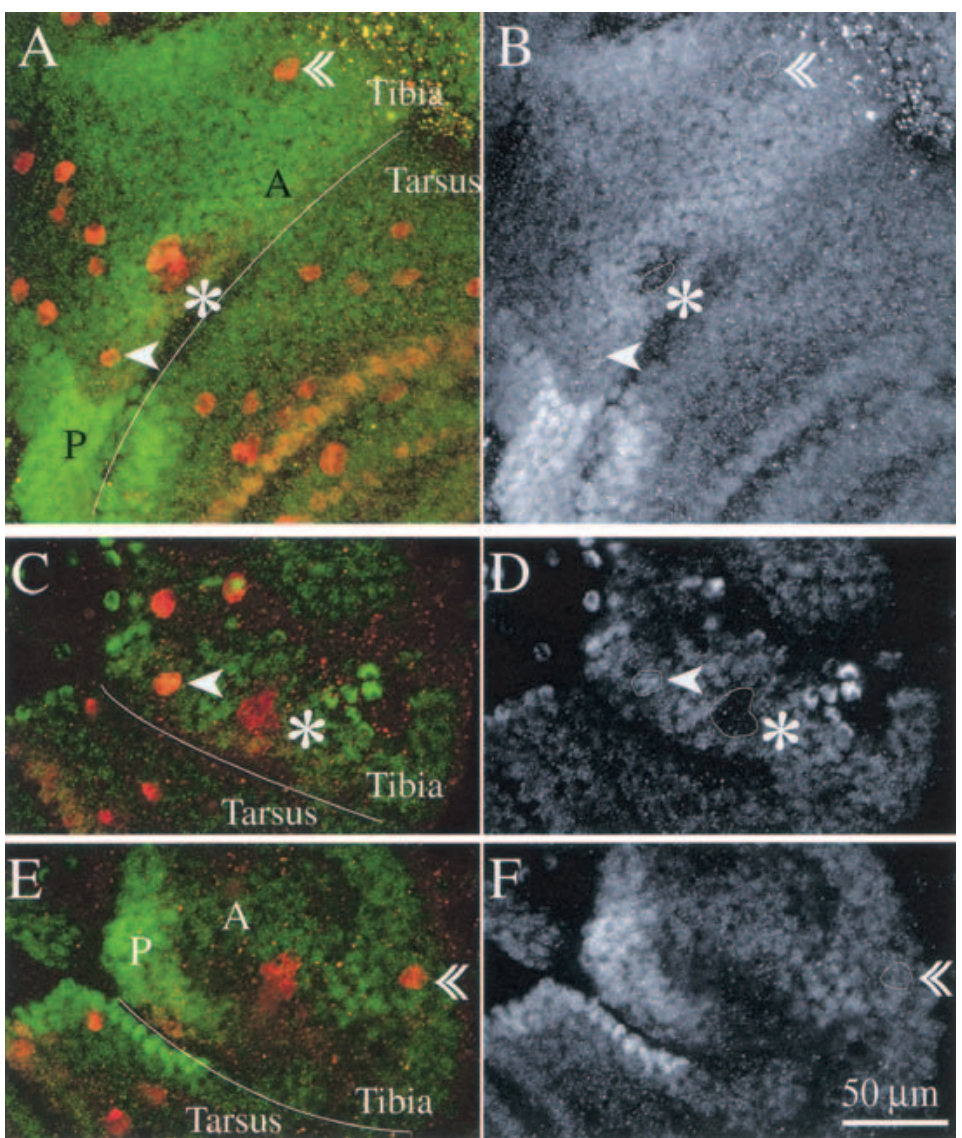

Figure 7. Ubx protein levels are modulated in the third leg epithelium, but the levels in apical and preapical bristle precursors are similar. Confocal images of distal tibia and basitarsus of third leg of neu-lacZ flies $2.5 \mathrm{~h}$ $\operatorname{APF}(A, B)$ and $4.5 \mathrm{~h} \mathrm{APF}(C-F)$. In green and right-hand panels anti-Ubx staining; in red anti- $\beta$-galactosidase staining. $(A, B)$ Third leg $2.5 \mathrm{~h}$ APF. In the area reproduced here, Ubx protein levels are modulated: Expression is higher in posterior $(\mathrm{P})$ than anterior leg $(\mathrm{A})$; levels are higher in anterior distal tibia than anterior basitarsus; levels are reduced in anterior distal tibia in a dorsal strip containing sensory organ precursors and in the invaginating cells of the tibial chordotonal organ (see outline marked by asterisk in $B$ ). The first-order precursors of apical (arrowhead) and preapical bristle (double arrowhead) show similar levels of Ubx expression (see outlines marked with arrowheads in $B) .(C, D)$ Dorsal and $(E, F)$ ventral aspects of distal tibia and basitarsus of a third leg at $4.5 \mathrm{~h} \mathrm{APF}$. By this time, the second-order precursors of apical and preapical bristle have formed. Ubx levels in these precursors are still comparable; Ubx levels in the tibial-chordotonal organ remain reduced (see outlines marked with arrowheads respectively asterisk in $D$ and $F$ ).
Other bristles not affected by the prolonged ectopic expression of Ubx in this regime include the ventral and dorsal mechanosensory microchaetes on the distal tibia. The dorsal microchaetes lie in a space between two rows of chemosensory bristles, the precursors for which demarcate the border of the domain of ectopic Ubx expression driven by $d p p$-Gal4 in the leg disc (Fig. 6D). All of 24 legs surveyed showed mechanosensory bristles in this domain (e.g., Fig. 6H). Thus, continuous ectopic Ubx expression does not halt the development of these bristles. In conclusion, the specificity of the response of the apical bristle precursors to Ubx expression is not explained by a particular profile of Ubx expression.

\section{Ubx induces different morphological changes in the apical and preapical bristles}

Ectopic Ubx expression in the sensory organ lineage (Ubx isoform Ia driven by the $109-68$ Gal4 line at $18^{\circ} \mathrm{C}$ ) transforms the stout shaft characteristic of the normal preapical bristle on $\mathrm{T} 2$ to a much finer shaft characteristic of the preapical bristle on T3 (Fig. 8). The same regime of ectopic Ubx expression leaves the apical bristle largely unchanged (Fig. 8). Conversely, removal of Ubx protein from the preapical precursors on $\mathrm{T} 3$ causes them to form a stout shaft resembling the preapical bristle on T2 (Fig. 5).

Other bristles show specific responses to Ubx expres- sion, but in the opposite direction to that of the preapical bristle: the short and relatively thin bristles on the T2 ventral basitarsus can be transformed by ectopic Ubx expression in the sensory organ lineage to long thick

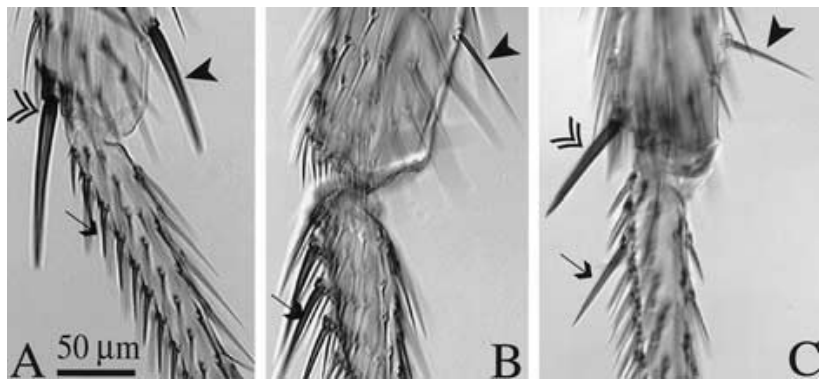

Figure 8. Ectopic Ubx expression in the sensory organ lineage has different effects on bristle morphology depending on bristle identity or bristle location. (A) Wild-type second leg and $(B)$ wild-type third leg. $(C)$ Second leg in which Ubx has been expressed in the sensory organ lineage with the 109-68 Gal4 driver at $18^{\circ} \mathrm{C}$. In the ectopic Ubx expression regime $(C)$, the stout preapical bristle on $\mathrm{T} 2$ is transformed toward the morphology of the thin preapical bristle normally found on T3 (arrowhead), whereas short bristles on the ventral basitarsus of $\mathrm{T} 2$ can be transformed toward the long stout morphology of those on the T3 leg (arrows). The morphology of the T2 apical bristle remains largely unchanged in this ectopic Ubx expression regime (double arrowhead). 
bristles, similar to those found on the T3 leg at this position (Fig. 8).

\section{Discussion}

Hox genes lie at the core of morphological diversification along the anteroposterior body axis. One Hox gene can control a multitude of traits that differ between segments, involving many different cell types and developmental pathways. To dissect aspects of this complexity, we have studied the segment-specific development of a class of organs that are repeated at many places within each segment-the mechanosensory bristles. Some representatives of this class are similar between segments, whereas others are restricted to certain segments, or show morphological variation between segments. We concentrated on individual large mechanosensory bristles which occur at a characteristic position in each segment. On the third thoracic segment, $U b x$ suppresses the development of some of these bristles and modifies the morphology of others.

\section{Mechanisms of interference of $\mathrm{Ubx}$ with bristle development}

For two particular bristles whose development is suppressed on T3, we find that $U b x$ acts directly on steps in sensory organ development, and not at some earlier stage of pattern formation.

In the two cases studied, it acts at different points in the hierarchy of sensory organ development. Development of the posterior sternopleural bristle is intercepted in midthird larval instar, shortly after initiation of a sternopleural proneural cluster. $U b x$ function is required at and restricted to this phase. Development of the tibial apical bristle is intercepted at $4.5-5 \mathrm{~h} \mathrm{APF}$, at the secondorder precursor stage. However, the requirement for $U b x$ is not limited to this phase of sensory organ development. To suppress the apical bristle, $U b x$ function is required both in the second-order precursor cells, and prior to mother cell specification, possibly in the proneural cluster. $U b x$ accomplishes apical bristle suppression on T3 by additive mechanisms which are temporally separated.

It was previously suggested that the placement of segment-specific sensory organs would likely be executed by the interaction of Hox genes with the discrete regulatory elements of the AS-C complex that integrate prepattern factors to locate individual proneural clusters (Gerhart and Kirschner 1997). Our results suggest that no exclusive preference has been given to this mechanism. For both apical and sternopleural bristles, a proneural cluster is initially specified but later developmental steps are blocked.

We suggest that interactions between homeotic genes and sensory organ development have evolved independently on many occasions, affecting different molecular steps. We have not found evidence for a potential constraint in respect to mechanisms of bristle suppression.
Evolution appears to have fixed a specific interaction between $U b x$ and the developmental pathway of individual bristles, not affecting other morphological features.

\section{The specificity of Ubx function in bristle development}

Ubx blocks the development of some bristles on the third thoracic segment (sternopleural bristles, edge bristle, apical bristle). It alters the morphology of others (preapical bristle, ventral basitarsal row). Yet other bristles are indistinguishable on the second and third thoracic segments, which suggests that they are unaffected by $U b x$. It is not likely that the proneural genes or later acting genes controlling bristle development provide this specificity, for all of these mechanosensory bristles express the same subset of known neural markers.

The differences in $U b x$ action might in principle result from the differential expression of Ubx in different bristle lineages within the T3 segment. Spatiotemporal regulation of this type allows $U b x$ to define the specific segment morphologies of both third thoracic and first abdominal segments during larval development (Castelli-Gair et al. 1994), and instructs the distribution of trichomes during pupal leg development (Stern 1998).

However, our data suggest that the regulation of Ubx levels within the third leg disc does not play a role in eliciting the differential response of sternopleural, apical, and preapical bristles. Ubx levels are similar in the first- and second-order precursors of the apical and preapical bristles (Fig. 7). Moreover, the ectopic expression of Ubx does not eliminate their specific responses even though it imposes essentially the same profile of Ubx expression on a number of domains from which different bristles will arise. We have seen this in the regime of ectopic Ubx expression directed by the $d p p$-Gal4 driver, which results in the suppression of the apical but not the preapical bristle (Fig. 6). Similarly ubiquitous ectopic expression of Ubx in $\mathrm{T} 2$ during the last $24 \mathrm{~h}$ of the third larval instar consistently suppresses the sternopleural bristle precursor, but none of the seven other bristle precursors segregating at this time in the periphery of the leg disc (data not shown).

Other factors that are differentially distributed in the disc will provide bristles with individual identities, and so restrict $U b x$ action. Leg patterning is already well advanced at the late larval and early pupal stages when $U b x$ intercepts bristle development. Numerous molecular markers, many of them transcription factors, demonstrate the subdivision of the proximodistal axis into a number of domains (e.g., Abu-Shaar and Mann 1998). Prospective joint territories are marked by complex gene expression patterns (e.g., Rauskolb and Irvine 1999). Decapentaplegic (Dpp) and Wingless (Wg) signaling pathways are active in dorsal and ventral leg territories, respectively (Brook and Cohen 1996). Any one of these factors may act combinatorially with $U b x$ to control the targets that modify bristle development.

Held and Heup (1996) showed that wg null clones induced on the ventral side of the leg eliminate the apical bristle and result in the development of a second preapi- 
cal bristle. Conversely, $d p p$ null clones on the dorsal side of the leg eliminate the preapical bristle and cause the formation of a second apical bristle. Clones that constitutively activate the Wg pathway (shaggy null clones) can result in ectopic apical bristle formation on the dorsal side of the leg next to the wild-type preapical bristle (Wilder and Perrimon 1995). This demonstrates an intimate link between dorsal or ventral cell identity and sensory organ patterning and identity. However, we cannot conclude from these results that $w g$ or $d p p$ are directly involved in modulating $U b x$ effects on bristle development.

The idea that individual macrochaetes have distinct molecular identities is supported by the observation that many have unique morphologies. In some cases, this is further documented by the branching pattern of their associated neurons in the leg neuromere. For example, whereas most mechanosensory bristles show either anterior or posterior branching in the neuromere, the apical bristle has a C-shaped branching pattern extending into both the anterior and posterior neuromere (Murphey et al. 1989). These distinct molecular identities are constituted by or derived from the fine-patterning of the leg that is generated during larval and pupal stages.

We propose that the specific effects of $U b x$ on sensory organ development depend on these additional factors. We can then comprehend how a single homeotic gene can specify the complex differences in sensory organ distribution and sensory organ morphology that characterize the legs and other body surfaces. The generic sensory organ program is unresponsive to the homeotic protein on its own; only in the context of other patterning information is an instruction conveyed. This allows for specific responses to the Hox gene to be elicited locally, affecting one or a small group of sensory organs, and not all organs of the same class throughout the segment.

\section{Materials and methods}

\section{Staging of animals}

The main reference point for staging animals was the time of puparium formation, defined as the white prepupa. White prepupae were selected as motionless animals with everted spiracles, but retaining a white puparium. This stage lasts about 30 min. For experiments on third instar larvae, the age at the time of experimental intervention was back-calculated from the time at which they formed a puparium. All stages are given for development at $25^{\circ} \mathrm{C}$.

\section{Immunocytochemistry}

For staining of larval discs, larvae were dissected in phosphate buffered saline (PBS; $\mathrm{pH}$ 7.4) and turned inside out; internal organs were then removed. For staining of prepupal discs, the cuticle of the pupal case was opened at the posterior end and removed in rings. All inner organs were removed until only the brain surrounded by the evaginating imaginal discs was left in the anterior pupal case. The discs were then incubated in solutions in this pupal case basket. Dissected specimens were collected in a vial of $4 \%$ paraformaldehyde on ice and then fixed for
20 min at RT on a shaker. Washes before incubation with primary and secondary antibodies were in PBS with $0.3 \%$ Triton $\mathrm{X}-100$ and $0.2 \%$ goat serum (PBST with GS). Incubation with the primary antibodies was generally overnight at $4^{\circ} \mathrm{C}$ and with the secondary antibodies for 4-6 h at RT. Stained specimens were dissected, recording leg disc identity, and mounted in Vectashield (Vector Laboratories). Sensory organs were monitored by anti- $\beta$-gal staining in the neu ${ }^{A 101}$ lacZ line P $\{1 A r B\}$ neu[A101] (Huang et al. 1991). Anti- $\beta$-gal antibodies were mouse (Promega) 1/100 and rabbit (Cappel) 1/1000. Anti-Cut antibody (rat) (Blochlinger et al. 1990) was used at a dilution of $1 / 200$ to stain external sensory organ precursors, and anti-Poxneuro antibody (rabbit) (Bopp et al. 1989) was used at a dilution of $1 / 100$ to stain chemosensory organ precursors. Ubx levels were monitored with anti-Ubx antibody FP 3.38 (mouse monoclonal) (White and Wilcox 1984) used at a dilution of $1 / 25$ to $1 / 100$. Secondary antibodies were Cy5-conjugated anti-rat and anti-rabbit (Jackson Laboratories), FITC-conjugated anti-mouse and Texas Red-conjugated anti-rabbit (Vector Laboratories) used at dilutions of $1 / 100$ or $1 / 200$.

\section{Confocal imaging}

Confocal z-series were taken with a Bio-Rad 1024 confocal microscope or a Leica SP confocal microscope. The distance between sections in series was $0.5 \mu \mathrm{m}$. Projections of sections taken at the Bio-Rad confocal were produced with the software Laser Sharp. We generated single views within the software using the replicate projection mode. Projections of sections taken at the Leica confocal were generated with the projection option in the Leica TCS NT confocal software.

\section{Time series of sternopleural proneural cluster development}

GFP expression driven by a sca-Gal4 line was used for monitoring proneural cluster development during the third larval instar. We crossed the w; D1-8a2 arIII UAS-GFP 65/167/TM6B line (gift from Dr. Andrea Brand) and the P\{GawB\} sca[537.4] line (Hinz et al. 1994). Egg laying and rearing of larvae were on apple juice plates with yeast. Samples from a cohort of larvae moulting to the third instar during a $6 \mathrm{~h}$ period were dissected at different time points. Their siblings were allowed to develop to puparium formation, and scored to provide an estimate of the age of the samples BPF. The peak of puparium formation was estimated to be $47 \mathrm{~h}$ after the midpoint of the second to third instar moult, with a spread of approximately $12 \mathrm{~h}$. We estimate that at the three times of sampling, the age range of the larvae will have been approximately $31-22,25-16$, and $11-0 \mathrm{~h}$ BPF.

\section{Scoring of bristle phenotypes in the adult}

Specific bristles were identified on the animals by position, bristle morphology, and the presence or absence of an accompanying bract. All mechanosensory microchaetes on the distal tibia show a dorsally located bract. Chemosensory bristles are recurved and have no bract associated with them. Apical and preapical bristles also do not have a bract associated with them, while each of the spurs on the second leg is accompanied by a bract.

Flies were preserved in $70 \%$ ethanol $/ 30 \%$ glycerol. For analysis of bristle development following ectopic Ubx expression, legs were examined under a compound microscope. For this purpose, legs were dissected in $70 \%$ ethanol $/ 30 \%$ glycerol, dried on filter paper, and then mounted in Hoyer's medium (Stern and Sucena 2000). The bristle pattern was scored under bright-field 
illumination. For quantitative analysis of $U b x$ null clones, flies were scored under a dissecting scope at 50× magnification.

\section{Manipulation of Hox gene expression}

Heatshock-Ubx expression For timed ectopic Ubx expression, we used the hs-Ubx-Ia line (original stock: w1118; HsUbx Ia/ TM3) (Mann and Hogness 1990). We generated flies of the genotype hs-Ubx Ia/neu-LacZ for monitoring sensory organ precursor development. Heatshocks were applied at $37^{\circ} \mathrm{C}$ for a duration of 45 to $60 \mathrm{~min}$ by incubating culture tubes in a waterbath. The heatshock regimes used for the ectopic expression of Ubx were the following: For the startpoint at $23 \pm 1 \mathrm{~h} \mathrm{BPF}$ : $1 \mathrm{~h}$ heatshock, $4 \mathrm{~h}$ at $25^{\circ} \mathrm{C}, 1 \mathrm{~h}$ heatshock, $5 \mathrm{~h}$ at $25^{\circ} \mathrm{C}, 1 \mathrm{~h}$ heatshock, and final transfer to $25^{\circ} \mathrm{C}$. For the startpoint at $21 \pm 1$ h BPF: $1 \mathrm{~h}$ heatshock, $4 \mathrm{~h}$ at $25^{\circ} \mathrm{C}, 45 \mathrm{~min}$ heatshock, and final transfer to $25^{\circ} \mathrm{C}$. For the startpoint $6 \pm 1 \mathrm{~h} \mathrm{BPF}$, conditions were: one heatshock for $1 \mathrm{~h}$ and final transfer to $25^{\circ} \mathrm{C}$. Ubiquitous ectopic Ubx expression in the third instar impairs puparium formation. Larvae become immobile but the puparium is not properly formed. Therefore, staging of the animals at the time of the heatshock cannot be done as usual by collecting white prepupae at a certain time after the heatshock. Instead, immobile third instar larvae were collected and dissected. The age of the dissected specimens was assigned according to the degree of imaginal disc eversion observed. Imaginal disc eversion begins in the white prepupa and is a certain indication that this developmental stage has been reached. Specimens were included in the sample only if they showed some but not advanced leg disc eversion. These discs will range in age from 0 to $\sim 2 \mathrm{~h} \mathrm{APF}$.

Expression patterns of the Gal4 lines employed for Ubx null clone induction or ectopic Ubx expression

We employed the Gal4-UAS system for targeted gene expression (Brand and Perrimon 1993).

dpp-Gal4: P \{Gal4-dpp.blk1\} (Staehling-Hampton et al. 1994). Driven by $d p p-G a 14, \mathrm{Ubx}$ is expressed in a robust dorsal stripe and a more patchy ventral stripe in the leg. We used Ubx isoforms Ia and IVa (lines UAS-Ubx Ia1 and UAS-Ubx IVa1; Reed 1996). At $18^{\circ} \mathrm{C}$, ectopic Ubx expression covers only the preapical bristle precursors. At $25^{\circ} \mathrm{C}$, the stripes of ectopic Ubx cover the sternopleural, preapical, and apical bristle precursors. Continuous animal rearing after embryogenesis at $25^{\circ} \mathrm{C}$ results in severe leg malformations. For these reasons, we shifted animals from $18^{\circ} \mathrm{C}$ to $25^{\circ} \mathrm{C} 40-50 \mathrm{~h} \mathrm{BPF}$.

sca-Gal4: P\{GawB\} sca[537.4] (Hinz et al. 1994). sca-Gal4 drives expression in proneural clusters and in the sensory organ lineage (Wang et al. 1997). In the presumptive domain of the sternopleural proneural cluster, no sca-Gal4 activity is detected during third larval instar prior to $22 \mathrm{~h} \mathrm{BPF}$ (observation from "time series of sternopleural proneural cluster development"). This ensures that clone induction with this line is only initiated on the sternopleurum when the proneural cluster forms.

109-68 Gal4: P \{Gal4\} sca[109-68] (Guo et al. 1996). For the majority of sensory organs in the leg discs, the 109-68 Gal4 line drives expression in the sensory organ lineage from the firstorder precursor onwards. We assayed this by activating GFP expression with this line and costaining for $\beta$-galactosidase in the neu-1acZ background. To obtain a summary picture of 10968 Gal4 activity in the leg disc we used a FRT-LacZ construct (Act5C FRT Draf+ FRT nuc-lacZ; Struhl and Basler 1993) which we activated permanently with this driver via a UAS-Flipase construct. This experiment closely mimics our experimental clone induction regime (see below). We observed the lacZ pat- tern in second and third leg APF. We found that first-order precursors of the apical bristle exhibit very low levels of lacZ, whereas second-order precursors show moderate levels. This suggests that 109-68 Gal4 expression is initiated in the firstorder precursors. In addition, in the majority of cases (11 of 12), no other lacZ-positive cells displaying similar lacZ levels are found adjacent to the apical bristle precursors. Thus, we are confident that clone induction with this driver is targeted to the apical bristle sensory organ lineage.

\section{Ubx null clone induction}

For clone induction, we made use of the FLP-FRT system (Golic and Lindquist 1989; Golic 1991). Two variants of Flipase-mediated $U b x$ null clone induction were employed. One relied on heatshock to induce Flipase, the other on Flipase expressed under the control of Gal4 lines expressed in proneural clusters or in the sensory organ lineage. Timed $U b x$ null clones were induced by heatshock of $1 \mathrm{~h}$ at $37^{\circ} \mathrm{C}$. No background clone induction was observed in flies raised at $25^{\circ} \mathrm{C}$. The allele of $U b x$ used was $U b x^{1}$, a null allele of the $U b x$ locus (Lindsley and Zimm 1992). As a marker for $U b x$ null clones in bristles, we used $S b$. Mitotic recombination facilitated by the FRT sites generates cells which are deficient for $U b x$ and wild-type for $S b$. Wildtype bristle shafts can easily be scored in an $S b$ heterozygous background. An exception to this is the preapical bristle on T3. Its morphology is very similar in $S b$ heterozygotes and wildtype animals. $U b x$ null clones of this bristle were scored by their phenotypic transformation to $\mathrm{T} 2$ preapical bristles.

The original stocks used to construct composite stocks for clone induction were:

scabrous-Gal4: P\{GawB\} sca[537.4] (Hinz et al. 1994)

109-68 Gal4: P \{Ga14\} sca[109-68] (Guo et al. 1996)

UAS-Flp: yw; p UAS-Flp, w+] Pin/CyO (Frise et al. 1996)

Hs-FLP: yw; P\{hsFLP22\} (Baonza et al. 2000)

FRT82: yw; $P[$ ryt, hs-neo, FRT $] 82 B$

FRTSb: w; P[ry+, hs-neo, FRT] $82 B$ Sb[63b]/TM6B (Xu and Rubin 1993)

FRT82 Ubx ${ }^{1} e^{11}:$ w; P[ry+, hs-neo, FRT $] 82 B U b x^{1} e^{11} /$ TM6B

FRT82 Ubx ${ }^{1}$ : yw; P[ry+, hs-neo, FRT $] 82 B U^{2} b^{1} / T M 6 B$

Flies scored for $U b x$ null clones were of the genotypes: yw Hs-FLP; FRTSb/FRTUbx ${ }^{1}$

yw UAS-FLP; sca-Gal4; FRT Ubx ${ }^{1} e^{11} /$ FRTSb,

yw UAS-FLP; 109-68 Gal4; FRT Ubx $e^{1} e^{11} /$ FRTSb

Timed $U b x$ null clone induction via heatshock was before puparium formation. $U b x$ null clones were induced at different times during third instar larval development. Specimens were collected after heatshock as newly formed pupae over time intervals of 5-6 h. For the assessment of time of Ubx action in the suppression of sternopleural bristles on T3 we scored animals within each collection interval for the number of $U b x$ null anterior (SP1) and posterior (SP3) sternopleural bristles marked by $\mathrm{Sb}^{+}$and calculated the percentage of wild-type bristles per hemisegment. We plotted these percentages in relation to the midpoints of clone induction BPF in the different collection intervals (Fig. 2).

\section{Acknowledgments}

We thank Torsten Bossing, Andrea Brand, Gerard Campbell, Jose Casal, Yuh-Nung Jan, Todd Laverty, Peter Lawrence, Hilary Reed, Fernando Roch, Gerald Rubin, and David Stern for fly stocks. We thank Steve Jackson, Markus Noll, and Robert White for antibodies. Thanks to Fernando Roch, James CastelliGair, and Laurent Seugnet for critical reading of the manuscript. 
This work was supported by the Wellcome Trust and the Evangelisches Studienwerk Villigst.

The publication costs of this article were defrayed in part by payment of page charges. This article must therefore be hereby marked "advertisement" in accordance with 18 USC section 1734 solely to indicate this fact.

\section{References}

Abu-Shaar, M. and Mann, R.S. 1998. Generation of multiple antagonistic domains along the proximodistal axis during Drosophila leg development. Development 125: 3821-3830.

Akam, M. 1987. The molecular basis for metameric pattern in the Drosophila embryo. Development 101: 1-22.

Auerbach, C. 1936. The development of the legs, wings, and halteres in wild type and some mutant strains of Drosophila melanogaster. Proc. R. Soc. Edinb. B 58: 787-815.

Baonza, A., Roch, F., and Martin-Blanco, E. 2000. DER signaling restricts the boundaries of the wing field during Drosophila development. Proc. Natl. Acad. Sci. 97: 7331-7335.

Blochlinger, K., Bodmer, R., Jan, L.Y., and Jan, Y.N. 1990. Patterns of expression of Cut, a protein required for external sensory organ development in wild-type and cut mutant Drosophila embryos. Genes \& Dev. 4: 1322-1331.

Bopp, D., Jamet, E., Baumgartner, S., Burri, M., and Noll, M. 1989. Isolation of two tissue-specific Drosophila paired box genes, Pox meso and Pox neuro. EMBO J. 8: 3447-3457.

Brook, W.J. and Cohen, S.M. 1996. Antagonistic interactions between Wingless and Decapentaplegic responsible for dorsal-ventral pattern in the Drosophila leg. Science 273: 13731377.

Brower, D.L. 1987. Ultrabithorax gene expression in Drosophila imaginal discs and larval nervous system. Development 101: 83-92.

Casares, F. and Mann, R.S. 1998. Control of antennal versus leg development in Drosophila. Nature 392: 723-726.

Castelli-Gair, J., Greig, S., Micklem, G., and Akam, M. 1994. Dissecting the temporal requirements for homeotic gene function. Development 120: 1983-1995.

Chasan, R. and Anderson, K.V. 1993. Maternal control of dorsalventral polarity and pattern in the embryo. In The development of Drosophila melanogaster (ed. M. Bate and A. Martinez Arias), pp. 387-424. Cold Spring Harbor Laboratory Press, Cold Spring Harbor, NY.

Cohen, S.M. 1993. Imaginal disc development. In The development of Drosophila melanogaster (ed. M. Bate and A. Martinez Arias), pp. 747-841. Cold Spring Harbor Laboratory Press, Cold Spring Harbor, NY.

Culi, J. and Modolell, J. 1998. Proneural gene self-stimulation in neural precursors: An essential mechanism for sense organ development that is regulated by Notch signaling. Genes \& Dev. 12: 2036-2047.

Frise, E., Knoblich, J.A., Younger-Shepherd, S., Jan, L.Y., and Jan, Y.N. 1996. The Drosophila Numb protein inhibits signaling of the Notch receptor during cell-cell interaction in sensory organ lineage. Proc. Natl. Acad. Sci. 93: 11925-11932.

Gerhart, J. and Kirschner, M. 1997. Cells, embryos, and evolution. Blackwell Science, Maldem, MA.

Gho, M., Bellaiche, Y., and Schweisguth, F. 1999. Revisiting the Drosophila microchaete lineage: A novel intrinsically asymmetric cell division generates a glial cell. Development 126: 3573-3584.

Golic, K.G. 1991. Site-specific recombination between homologous chromosomes in Drosophila. Science 252: 958-961.

Golic, F.G. and Lindquist, S. 1989. The FLP recombinase of yeast catalyses site-specific recombination in the Dro- sophila genome. Cell 59: 499-509.

Gomez-Skarmeta, J.L., Rodriguez, I., Martinez, C., Culi, J., Ferres-Marco, D., Beamonte, D., and Modolell, J. 1995. Cisregulation of achaete and scute: Shared enhancer-like elements drive their coexpression in proneural clusters of the imaginal discs. Genes \& Dev. 9: 1869-1882.

Gorfinkiel, N., Morata, G., and Guerrero, I. 1997. The homeobox gene Distal-less induces ventral appendage development in Drosophila. Genes \& Dev. 11: 2259-2271.

Goto, S. and Hayashi, S. 1997. Specification of the embryonic limb primordium by graded activity of Decapentaplegic. Development 124: 125-132.

Guo, M., Jan, L.Y., and Jan, Y.N. 1996. Control of daughter cell fates during asymmetric division: Interaction of Numb and Notch. Neuron 17: 27-41.

Heitzler, P. and Simpson, P. 1991. The choice of cell fate in the epidermis of Drosophila. Cell 64: 1083-1092.

Held, L.I. and Heup, M.A. 1996. Genetic mosaic analysis of decapentaplegic and wingless gene function in the Drosophila leg. Dev. Genes Evol. 206: 180-194.

Hinz, U., Giebel, B., and Campos-Ortega, J.A. 1994. The basichelix-loop-helix domain of Drosophila lethal of scute protein is sufficient for proneural function and activates neurogenic genes. Cell 76: 77-87.

Huang, F., Dambly-Chaudiere, C., and Ghysen, A. 1991. The emergence of sense organs in the wing disc of Drosophila. Development 111: 1087-1095.

Lewis, E.B. 1963. Genes and developmental pathways. Am. Zool. 3: 33-56.

. 1978. A gene complex controlling segmentation in Drosophila. Nature 276: 565-570.

Lindsley, D.L. and Zimm, G.G. 1992. The genome of Drosophila melanogaster. Academic Press, San Diego, CA

Mann, R.S. and Hogness, D.S. 1990. Functional dissection of Ultrabithorax proteins in D. melanogaster. Cell 60: 597-610.

Martinez Arias, A. 1993. Development and patterning of the larval epidermis of Drosophila. In The development of Drosophila melanogaster (ed. M. Bate and A. Martinez Arias), pp. 517-608. Cold Spring Harbor Laboratory Press, Cold Spring Harbor, NY.

Murphey, R.K., Possidente, D.R., Vandervorst, P., and Ghysen, A. 1989. Compartments and the topography of leg afferent projections in Drosophila. I. Neurosci. 9: 3209-3217.

Nottebohm, E., Usui, A., Therianos S., Kimura K., DamblyChaudiere C., and Ghysen, A. 1994. The gene poxn controls different steps of the formation of chemosensory organs in Drosophila. Neuron 12: 25-34.

Rauskolb, C. and Irvine, K.D. 1999. Notch-mediated segmentation and growth control of the Drosophila leg. Dev. Biol. 210: 339-350.

Reed, H. 1996. "The role of alternatively spliced microexons and hexapeptide motif in modulating $U b x$ specificity in vivo." Ph.D. thesis, Department of Genetics, University of Cambridge, Cambridge, UK.

Roch, F. and Akam, M. 2000. Ultrabithorax and the control of cell morphology in Drosophila halteres. Development 127: 97-107.

Singson, A., Leviten, M.W., Bang, A.G., Hua, X.H., and Posakony, J.W. 1994. Direct downstream targets of proneural activators in the imaginal disc include genes involved in lateral inhibitory signaling. Genes \& Dev. 8: 2058-2071.

Staehling-Hampton, K., Jackson, P.D., Clark, M.J., Brand, A.H., and Hoffmann, F.M. 1994. Specificity of bone morphogenetic protein-related factors: Cell fate and gene expression changes in Drosophila embryos induced by decapentaplegic but not 60A. Cell Growth Differ. 5: 585-593. 
Stern, D. 1998. A role of Ultrabithorax in morphological differences between Drosophila species. Nature 396: 463-466.

Stern, D. and Sucena, E. 2000. Preparation of larval and adult cuticles for light microscopy. In Drosophila protocols (eds. W. Sullivan, M. Ashburner, and R.S. Hawley), pp. 601-615. Cold Spring Harbor Laboratory Press, Cold Spring Harbor, NY.

Struhl, G. and Basler, K. 1993. Organizing activity of wingless protein in Drosophila. Cell 72: 527-540.

Stuart, J.J., Brown, S.J., Beeman, R.W., and Denell, R.E. 1991. A deficiency of the homeotic complex of the beetle Tribolium. Nature 350: 72-74.

Usui, K. and Kimura, K. 1992. Sensory mother cells are selected from among mitotically quiescent cluster of cells in the wing disc of Drosophila. Development 116: 601-610.

Vachon, G., Cohen, B., Pfeifle, C., McGuffin, M.E., Botas, J., and Cohen, S.M. 1992. Homeotic genes of the Bithorax complex repress limb development in the abdomen of the Drosophila embryo through the target gene Distal-less. Cell 71: 437450.

Wagner-Bernholz, J.T., Wilson, C., Gibson, G., Schuh, R., and Gehring, W.J. 1991. Identification of target genes of the homeotic gene Antennapedia by enhancer detection. Genes \& Dev. 5: 2467-2480.

Wang, S., Younger-Shepherd, S., Jan, L.Y., and Jan, Y.N. 1997. Only a subset of the binary cell fate decisions mediated by Numb/Notch signaling in Drosophila sensory organ lineage requires Suppressor of Hairless. Development 124: 44354446.

Weatherbee, S.D., Halder, S., Kim, J., Hudson, A., and Carroll, S.B. 1998. Ultrabithorax regulates genes at several levels of the wing-patterning hierarchy to shape the development of the Drosophila haltere. Genes \& Dev. 12: 1474-1482.

Wheeler, M.R. 1981. The Drosophilidae: A taxonomic overview. In The genetics and biology of Drosophila (eds. M. Ashburner, H.L. Carson, and J.N. Thompson), pp. 1-97. Academic Press, London, UK.

White, R.A. and Wilcox, M. 1984. Protein products of the bithorax complex in Drosophila. Cell 39: 163-171.

Wilder, E. and Perrimon, N. 1995. Dual functions of wingless in the Drosophila leg imaginal disc. Development 121:477488.

Xu, T. and Rubin, G.M. 1993. Analysis of genetic mosaics in developing and adult Drosophila tissues. Development 117: $1223-1237$. 


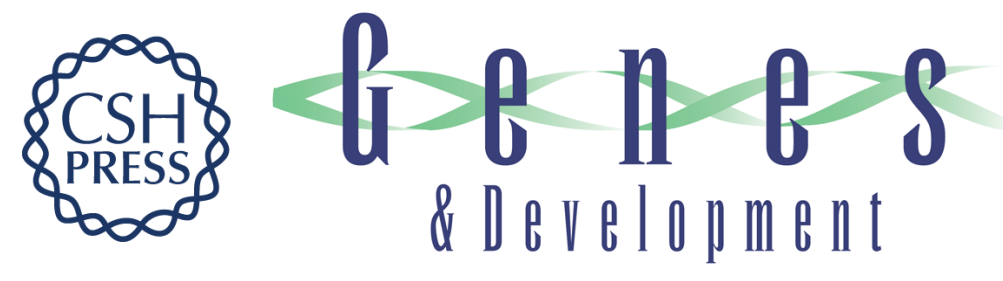

\section{Hox gene control of segment-specific bristle patterns in Drosophila}

Marion Rozowski and Michael Akam

Genes Dev. 2002, 16:

Access the most recent version at doi:10.1101/gad.219302

Supplemental
Material http://genesdev.cshlp.org/content/suppl/2002/05/09/16.9.1150.DC1

References This article cites 42 articles, 25 of which can be accessed free at: http://genesdev.cshlp.org/content/16/9/1150.full.html\#ref-list-1

License

Email Alerting Receive free email alerts when new articles cite this article - sign up in the box at the top Service right corner of the article or click here.

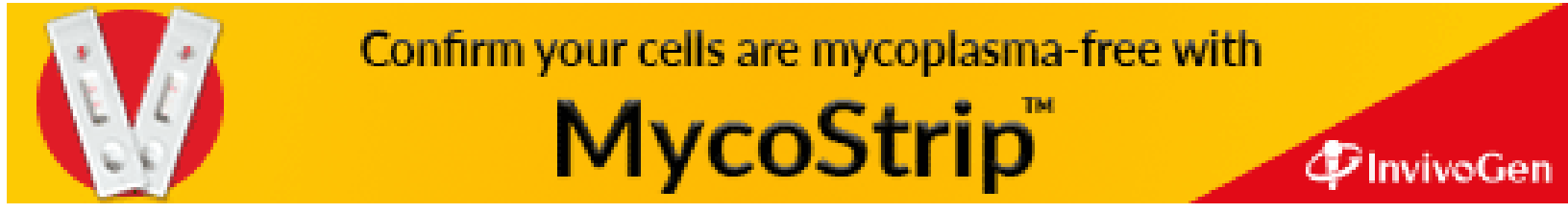

